nearly always involved. The fixed type of lupus erythematosus is the one most frequently complicated by epithelioma, the fleeting subacute or acute type generally escaping. It tends to appear in the scar tissue, and this dense, sclerotic, resistant tissue walls it off and accounts for the slow course of the disease. Adenopathy is usually late. Durand states that it is more common in males than in females, roughly in the proportion of 3 to 1 . He also states that the average age of onset is 51 years, the average interval before its appearance 19 years, and the most favourable period between 30 and 60 years.

Keutzer has considered the aetiology of the disease from three standpoints: (1) that the combination of lupus erythematosus and cancer is accidental ; (2) that the many treatments for such a chronic disease as lupus erythematosus ( $x$ rays, radium, $\mathrm{CO}_{2}$ snow) provoke the cancer; and (3) lupus erythematosus itself may give rise to the degeneration. The first of these cannot altogether be eliminated. Durand considers that $x$ rays and radium can be incriminated in only $35 \%$. Since over 100 cases have been described in which neither of these agents was used, it is a reasonable theory that the inflammatory changes which precede the atrophy of lupus erythematosus may lead unaided

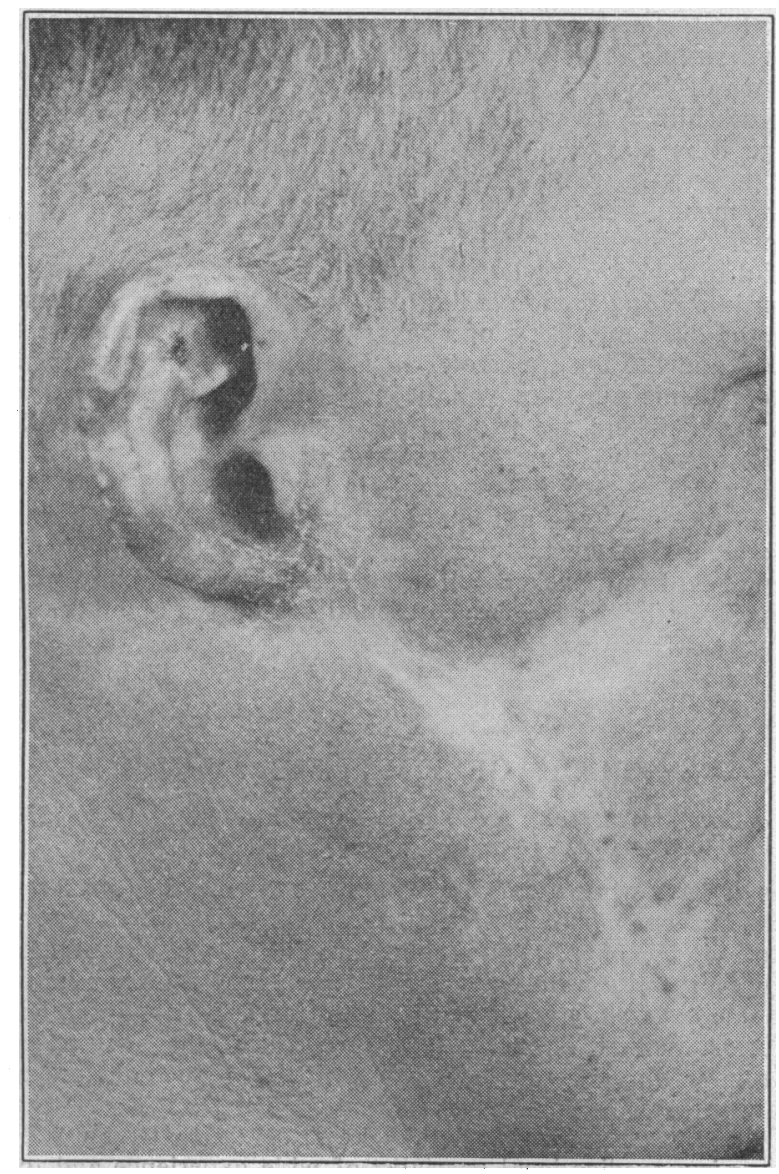

FIG. 2.-Photograph of the patient taken on June 5, 1946.

to epithelioma. The prognosis in these cases is not good, and Beeson and Ehert consider that wide excision is best. Alternatively, $x$ rays and radium can be combined with surgery.

\section{Report of a CASE}

In November, 1926, a man aged 22 first attended the skin department of the London Hospital, under the care of Dr. O'Donovan. His family history revealed nothing of value. On examination a fixed erythema with superficial white scaling of the nose and orbits was seen. Treatment consisted of $\mathrm{CO}_{2}$ snow, calamine lotion, and $1 \mathrm{gr}$. (65 mg.) of quinine sulphate thrice daily. In July, 1927, slight scarring of the left lobule occurred, and treatment was continued until July, 1928. In March, 1930, he had butterfly extension over the face, with both ears involved. This was treated by radium plate to all areas, piece by piece. In September, 1934, his own doctor began a series of fortnightly injections of "bismostab." From December, 1934, to January, 1936, the radium plate was applied to all areas. In March, 1938, the lesions were improved, and the improvement was maintained until June, 1943, when a few fresh lesions appeared on the nose. All lesions were treated with $\mathrm{CO}_{2}$ snow. A series of fifteen injections of bismostab given by his own doctor was completed in April, 1944. In the August there was no change, and three months later he had a course of "myocrisin" injections. In April, 1945, a small wart appeared on the lobule of the right ear, and was treated with $10 \%$ salicytic acid ointment. Next month podophyllin in oil, $25 \%$, was applied to the wart. In March, 1946, four keratinized warty growths appeared over the region of the lobe of the right ear and on to the adjoining skin of the cheek and neck-clinically squamous carcinoma type (Fig. 1). The patient was referred to the radiotherapy department of the London Hospital, where the diagnosis was confirmed and the epithelioma was treated with $x$ rays. On June 5, 1946, the area was quite healed and there was no sign of epithelioma (Fig. 2).

Charles Ryan, M.D.

\section{REFERENCES}

Beeson, B. B., and Ehert, M. H. (1934). Urol. cutan. Rev., 38, 785. Durand, Pierre. Quoted by Beeson and Ehert. Keutzer, F. Quoted by Beeson and Ehert. Pringle, J. J. (1900). Brit. J. Derm., 12, 1.

\section{Status Epilepticus after Electric Convulsion Therapy}

The following report of a rare complication of electric convulsion therapy is worthy of record.

\section{CASE History}

A married woman aged 60 was admitted to hospital on Sept. 28, 1946 , in a state of reactive depression. She was retarded, was not eating her food, and was confused, apathetic, and fidgety. She gradually ,improved, and at the time of her discharge on Nov. 23 (made at the request of a relative) she was able to take part in the activities of the ward. She was due to have E.C.T., but the machine was out of action during her stay in hospital. Her heart had been examined by a speciaiist and considered sound. With a change in the domestic circumstances she relapsed, and her consultant advised E.C.T. as an out-patient.

Treatment began on Jan. 24, 1947, and was given twice weekly. It was on a subconvulsive basis, as a number of cases had been successfully treated in this manner. The first application was 0.2 second, 80 volts. The voltage and time were gradually increased each week. Her improvement was not as one could have wished; therefore with the eighth and ninth treatments $(0.4$ second, 100 volts) convulsions were produced. A definite improvement in her mental state was noted by her relatives. The tenth treatment, on Feb. 25 (0.4 second, 100 volts), did not cause a convulsion. She lost consciousness, recovered rapidly, and was very alert afterwards.

Just over an hour later, while on her way home, she felt faint, and on alighting from a bus collapsed and had a convulsion. She was moved into a house near by and four more convulsions followed. She recovered consciousness about two hours later, at 8 p.m., and was removed home by ambulance at 8.30 p.m., remaining drowsy. The convulsions began again at 9.30 p.m., and after being seen by her consultant she was admitted to hospital at midnight in a comatose condition, having had eight convulsions. A ninth occurred on admission. Pethidine, $50 \mathrm{mg}$., was given intramuscularly and the convulsions ceased for just over two hours. They then started again, and 35 convulsions followed at approximately ten-minute intervals. Hyoscine, $1 / 200 \mathrm{gr}$. (0.32 mg.), was given at 3 a.m., 4 a.m., and 6 a.m., with little benefit. At 8.45 a.m. an amyl nitrite capsule was broken under the nostrils; this was followed shortly by 3 gr. $(0.2 \mathrm{~g}$.) of soiuble phenobarbitone intravenously. No further convulsions occurred from this time until her death in coma about thirty-six hours later. Her pupils remained fixed and dilated, acetone was detected in her breath, and air hunger was prominent at times. The temperature, pulse, and respirations were all raised, the temperature mounting to $104^{\circ} \mathrm{F}$. $\left(40^{\circ} \mathrm{C}\right.$.) on three occasions. Glucose and salines were given intravenously during the thirty-six hour comatose state preceding death, and for a time she improved. Digitalis was given hypodermically. However, her condition deteriorated and she died at 11.25 p.m. on Feb. 27.

A post-mortem examination was made by Dr. Janes at the Royal Sussex County Hospital, Brighton, on March 1. He detected multiple minute haemorrhages confined to the right side of the brain. Purulent bronchitis and terminal hypostasis were also present.

I am indebted to Dr. Alexander Watt for help in the preparation of this report and for permission to publish. 